\title{
Competency Based Assessment in Dynamics
}

\section{Dr. Kurt M DeGoede, Elizabethtown College}

Professor of Engineering and Physics, Elizabethtown College. His research interests in biomechanics include developing clinical instruments for rehabilitation. Dr. DeGoede teaches upper-level undergraduate mechanical engineering and design courses and the first-year introduction to engineering course. He is also developing a collaborative study abroad program in West Africa built around social enterprise initiatives. 


\title{
Competency-Based Assessment in Dynamics
}

\begin{abstract}
This paper examines the effectiveness and limitations of implementing a competency-based grading system in Engineering Dynamics. Rather than assessing the students on how well they performed the many skills studied (traditional grading system) students were assessed on how many skills they can do well (competency or mastery-based grading).

To earn a passing grade in the competency-based grading system, students demonstrated proficiency on two foundational skills for dynamic analysis. Proficiency required solving a problem in a test environment, assessed as correct or containing only trivial errors. In our curriculum, prerequisites are met with a grade of C- or higher. To earn this grade, students must have further demonstrated competency in two additional skills, determined as required for continued advanced study in dynamics. Students could demonstrate proficiency on additional skills to earn higher grades. Each skill increased the final letter grade by $1 / 3$ of a grade.

Comparisons were made using the rate at which students demonstrated proficiency. Competency-based offerings of the course were compared to a similar group of students assessed with a more traditional grading system (2014 offering). In the competency-based courses, $>93 \%$ of the students demonstrated proficiency on the required skills, compared to $43 \%$ in the traditional offerings (Chi-Squared $\mathrm{p}<0.01$ ).

Several aspects of course design can help foster the successful use of the competency-based system of assessment. A structure where the additional skills are not co-dependent for developing competency allows the course to have no more than two independent groups of students. A physical classroom environment conducive to managing parallel groups working on different sets of skills fosters effective use of class time. Students move at different rates, so the instructor must create frequent opportunities to demonstrate competencies.
\end{abstract}

\section{Objective}

This paper illustrates a structure ensuring all students moving forward in a curriculum demonstrate mastery of critical skills. The learning priority in a 300-level dynamics course was shifted from breadth to depth. A few years ago it was observed that while most of the middle 50\% students knew "sort of" how to do many things, they did not "actually" know how to do anything. First in 2014, the exams were rebuilt to emphasize particular skills within a traditional exam structure. Eighty percent of exam grades came from two (one each of four exams) specific skills. Performance on the emphasized skills did go up, but only marginally. Something more drastic was required. At this point, the course structure was transitioned to a competency/mastery-based grading system, and profound changes in student learning were observed. 


\section{Background on competency-based grading}

Others have reviewed Competency and Mastery-based learning, and the reader is referred to these papers for a full literature review. One of the most recent of those reviews focused on Competency Based Learning in Engineering [1]. They defined competency-based learning (CBL) as "an outcome-based, student-centered form of instruction where students progress to more advanced work upon mastering the necessary prerequisite content and skills” [1-4]. In a careful review of 60 published papers, they found evidence that there is increasing use of CBL, across all fields and in engineering [1, 5-7]. They also found "evidence to support its effectiveness in improving learning outcomes, meeting the needs of diverse student populations, and responding to industry's demands for competent engineers” [1].

CBL can take on a variety of alternative labels including most prominently Mastery-Based Learning [8]. These terms are used interchangeably here. The root of these methodologies emerges from the work of Benjamin Bloom who believed that all students could master the material in a given curriculum if they had sufficient time to do so [9-10]. Again, looking across the pedagogical research spanning many disciplines, researchers found that "compared with students in traditionally taught classes, students in well-implemented mastery learning classes consistently reach higher levels of achievement and develop greater confidence in their ability to learn and in themselves as learners” [9, 11-12]. Guskey described well-designed mastery-based learning as including

- Pre-assessments and pre-teaching: addressing prerequisite materials for the course at hand

- Group level initial instruction of new concepts and skills

- Regular formative assessments: frequent opportunities to demonstrate mastery and opportunities to learn from unsuccessful attempts

- Corrective instruction: individually coaching students as they work through learning the skills [9].

Two others have recently published examples of implementing CBL in mechanical engineering courses. Implementation in a statics course [13] and a fluid mechanics course [14] have been described. In the statics course, the researcher found that performance of students entering with lower indicators of success performed better than in traditional courses. The assessment basis for this judgment was a common final exam between a traditional offering of the course and the CBL version. For this implementation, students were allowed up to three attempts at each concept. For each successive attempt, the instructor used less difficult problems and awarded fewer points toward the final grade [13]. In the fluids course, the instructor allowed only two or three attempts on each skill but determined grades based on the number of skills mastered rather than a traditional 70/80/90 grading scale. The grading system used in this study determines grades based entirely on the number of skills mastered. The instructors in the fluids course found the process improved feedback on student performance to the instructor, simplified grading and provided direct links to ABET outcome assessments [14]. 


\section{Description of the Current Implementation}

Students earn grades based on the number of 11 skills (Table 1 ) for which they can demonstrate mastery. They demonstrate mastery by scoring an A- $(4.5 / 5)$ or higher on a single test problem according to the scale shown in Table 2. Students demonstrate computational skills: MATLAB ode45, and SimMechanics modeling, throughout of class take-home problems coupled with a one-on-one demonstration of competency with the tool.

Table 1: Skill Listing. This paper refers to the skills by the 2016 labels.

\begin{tabular}{|c|c|}
\hline 2017 Skills & 2016 Skills \\
\hline \multicolumn{2}{|l|}{ Primary Skills } \\
\hline $\begin{array}{l}\text { P1 - Rotate vector quantities between various } \\
\text { coordinate systems. } \\
\text { P2 - Work in polar coordinates. } \\
\text { P3 - Construct FBDs and Apply Newton's } \\
\text { laws of motion to set up equations of motion } \\
\text { for a system of } 1 \text { or } 2 \text { rigid bodies moving in } \\
\text { the plane. }\end{array}$ & $\begin{array}{l}\text { P1 - Construct an accurate/appropriate set of } \\
\text { FBDs for any system (1-3) of rigid bodies in } \\
\text { the plane. } \\
\text { P2 - Rotate vector quantities between various } \\
\text { coordinate systems and calculate derivatives } \\
\text { in any moving coordinate system. }\end{array}$ \\
\hline \multicolumn{2}{|c|}{ Required Skills (must pass all P skills before R skills improve grade) } \\
\hline $\begin{array}{l}\text { R1 - Utilize principles of energy and } \\
\text { momentum to solve for the motion of a } \\
\text { system of } 1 \text { or } 2 \text { bodies. } \\
\text { R2 - Take derivatives in moving coordinate } \\
\text { systems and calculate the velocities and } \\
\text { accelerations (linear and rotational) of } 2 \text { or } 3 \\
\text { interconnected rigid bodies. } \\
\text { R3 - Apply ode } 45 \text { to solve equations of } \\
\text { motion }\end{array}$ & $\begin{array}{l}\text { R1 - Calculate the velocities and } \\
\text { accelerations (linear and rotational) of } 2 \text { or } 3 \\
\text { interconnected rigid bodies. } \\
\text { R2 - Apply Newton's laws of motion to solve } \\
\text { for the motion of a system of } 1 \text { or } 2 \text { rigid } \\
\text { bodies moving in the plane. (Includes use of } \\
\text { P1.) }\end{array}$ \\
\hline \multicolumn{2}{|c|}{ Supplemental Skills (must pass all R skills before S skills improve grade) } \\
\hline $\begin{array}{l}\text { S1 - Analyze oblique impact between two } \\
\text { rigid bodies. } \\
\text { S2 - Solve for the kinetics of mass flow } \\
\text { systems. } \\
\text { S3 - Determine the angular momentum of a } \\
\text { rigid body moving in 3D. } \\
\text { S4 - Construct a model and perform analysis } \\
\text { of an assigned 2D system with } \\
\text { SimMechanics. } \\
\text { S5 - Complete kinetic analysis of a single } \\
\text { rigid body moving in 3D with SimMechanics } \\
\text { \{only available after completing S3\}. }\end{array}$ & $\begin{array}{l}\text { S1.1 - Analyze oblique impact between two } \\
\text { rigid bodies. } \\
\text { S1.2 - Utilize principles of energy and } \\
\text { momentum to solve for the motion of a } \\
\text { system of } 1 \text { or } 2 \text { bodies. } \\
\text { S2.1 - Solve for the kinetics of mass flow } \\
\text { systems. } \\
\text { S2.2 - Determine the angular momentum of a } \\
\text { rigid body moving in 3D. } \\
\text { S3.1 - Apply ode } 45 \text { to solve equations of } \\
\text { motion. } \\
\text { S3.2 - Construct a model and perform } \\
\text { analysis of an assigned } 2 \mathrm{D} \text { system with } \\
\text { SimMechanics. } \\
\text { S3.3 - Complete kinetic analysis of a single } \\
\text { rigid body moving in 3D with SimMechanics } \\
\text { \{must complete S2.2 } 1^{\text {st }} \text { \}. }\end{array}$ \\
\hline
\end{tabular}


Final course grades are then determined based on the number of skills mastered (Table 3). Students are also required to participate in daily discussions of assigned problems. Students were provided HW solutions at the time of assignment. Instead of submitting solutions students submit discussions and questions about the problem set on a web-based course management tool. All exams were taken using only basic equation packet and a calculator approved for use on the FE/PE exams (http://ncees.org/exams/calculator/).

Table 2: Grading Rubric.

\begin{tabular}{|l|l|}
\hline 5.0 & Correct (A) \\
\hline 4.5 & Trivial Errors (A-) \\
\hline 4.0 & Minor Conceptual Error (B/C) \\
\hline 3.0 & Major or Multiple Minor Conceptual Errors (D) \\
\hline 2.0 & Something was Correct $(\mathrm{F}+)$ \\
\hline 1.0 & Problem was Attempted (F) \\
\hline
\end{tabular}

The grading system evolved over several years. The skills as defined in 2017 were based on what was learned from the first offering of this course as a competency-based grading course in 2016. The motivation for the changes and the effect on the student outcomes are discussed below. Before 2016, the course was graded more traditionally. Each student took four exams covering specific topics and skills. All students moved forward to new skills regardless of performance on the previous exam. The 2016 mastery skills were based directly on the skills used in the previous offerings of the course, so the 2016 skill labels were used in the analysis below for comparisons across the two grading systems.

Table 3: Grading Scheme.

\begin{tabular}{|l|l|}
\hline Pass one P skill & D- \\
\hline Pass two P skills & D \\
\hline Pass all three P skills & D+ \\
\hline Pass one R skill & C- \\
\hline Pass two R skills & C \\
\hline Pass all three R skills & C+ \\
\hline Pass one S skills & B- \\
\hline Pass two S skills & B \\
\hline Pass three S skills & B+ \\
\hline Pass four S skills & A- \\
\hline Pass all five S skills & A \\
\hline
\end{tabular}

In our curriculum, prerequisites are met with a grade of C- or higher. Skills are selected based on the importance of mastery for continued study in mechanics. The supplemental skills (S-skills) are positioned at the top of the grading scheme, not because they are the most challenging, but because they are a critical foundation for the other topics or for moving forward in the curriculum beyond this course. In fact, many students find these S skills the easiest to demonstrate mastery. 
How the skills are chosen and positioned influence student mastery levels. In the 2017 offering, the appropriate use of principles of conservation of energy and momentum, skill S1.2, was emphasized over skills S1.1 (oblique impact) and S2.1 (mass flow), by moving S1.2 to an Rskill. After the 2016 offering of the course, it was decided that understanding the applications of skill S1.2 provided a needed ability to approximate behavior to increase qualitative understanding of the material and to better prepare all students for the sorts of analysis required on the FE exam. This shift had a profound effect on mastery rates.

\section{Classroom Sessions}

The course includes twenty-eight 80 minute sessions, plus a 3-hour final exam session. A full session was dedicated to introducing nine of the eleven skills (one session for each skill, distributed at regular intervals through the semester). The two SimMechanics (MATLAB Simscape Multibody) skills were introduced through a prerecorded tutorial available through the course management system.

The majority of the remaining sessions were labeled "Coaching Sessions.” At coaching sessions, students sat at tables of 4-6 and worked on applications from one of two skill sets (pre-selected practice problems). The individual tables of 4-6 students split into two groups. The course typically includes a total of 25-35 students. One group of tables always worked on the most recent skill introduced. The other group practiced previous skills. Often problems could be selected to span several of those skills. The instructor moved between the two groups every 1015 minutes, discussing the work and answering questions.

The course was designed with four exam dates, plus the final exam slot, where all students completed skill assessments. There were an additional 5 class sessions where students had the option to practice skills at a coaching session with the instructor, or in a separate room take one or more skill assessments under the supervision of a TA. In assessment sessions, students chose which skills they would attempt that day. Unique problems were generated for every skill on every assessment opportunity. All instructor solutions were posted after each assessment, and available to other students as additional practice. Students would build their exam picking up the problems they chose and stapling those behind a cover sheet. By the end of the semester, students had ten opportunities to demonstrate mastery of skills. Take home skills, requiring numerical modeling and simulations (MATLAB ode45 and Simscape) required students to select and model a unique problem (different system for every student) and then demonstrate proficiency with the tool through a paper quiz or a practicum evaluation with the instructor.

\section{Analysis of outcomes}

\section{Methods}

It was possible to compare the percentage of students who demonstrated mastery of particular skills across three-course offerings. The exam structure and available records from the 2014 course allowed for retrieval of performance measures from seven of the eleven 2016 skills (as shown in Figure 1). In 2014, Students had one or two opportunities to demonstrate mastery of each of the seven skills in an exam setting. Student performance across two offerings of 
mastery-based versions of the course 2016 and 2017 was also compared. Data for skill S1.2 was not available for the 2014 course, but due to the structural change noted above shifting emphasis toward this skill in 2017, this skill was also included in the analysis.

Since a score of 4.5 or higher (Table 2) indicated mastery of a skill, student performance was compared across course offerings by calculating a mastery ratio: the percentage of students scoring 4.5/5 or higher for each skill. Then using a chi-squared test, this mastery ratio was contrasted across the three offerings of the course, comparing the 2014 performance to the 2016 performance, and in a separate analysis comparing 2016 to 2017. Ratios were considered different if the p-value of the chi-squared test was less than 0.05 .

\section{Results}

Use of the Mastery Based Grading system significantly increased student mastery ratios for the $\mathrm{P}$ and R skills. The mastery ratio for 2016 was significantly higher for all three skills than in 2014. In the 2014 course, mastery ratios ranged from 42\% - 54\% for these three skills. In 2016 and 2017, all pass ratios were over 93\% for the same skills (Figure 1).

For the supplemental skills, performance was similar between 2014 and 2016. The only significant difference indicated higher performance on S3.1 in 2014 (88\%) than in 2016 (52\%).

As described above, shifting S1.2 to a Required Skill dramatically increased mastery of that skill in 2017, over the 2016 level, 88\%, and 34\% respectively. However, two other skills were adversely affected by this move. Skill S1.1 dropped from $90 \%$ to 62\%, and skill S2.2 dropped from $86 \%$ to $41 \%$.

\section{Discussion of proficiency rate analysis}

Not surprisingly, when requiring students to demonstrate mastery of particular skills, proficiency rates went up. In the traditional course higher percentages of students mastered skills that were straightforward and procedural: applying mass flow equations and solving for cases of oblique impact. In the mastery-based course, many students did not have time to move into work on these supplemental skills.

Effectively, the course has moved to a model favoring depth over breadth. All students are provided the time, practice and coaching they need to master the key skills. However, by doing so, many students do not practice all the skills typically covered in the course. All students do participate in one instructional session for each skill and complete one set of homework exercises for all but the two SimMechanics skills.

In the traditional course, many students did not master those skills identified as the fundamental skills of dynamics for our curriculum: those required for 2D planar kinetics. They simply needed more time. Since in the traditional approach all students moved through the topics with the same pacing, many students were unprepared for the next unit whenever that material built upon a foundation of the previous material. It is no wonder those students then struggled through the remainder of the semester - constantly trying to catch up. In the mastery graded course, students were provided more time and practice to master each of those skills. 


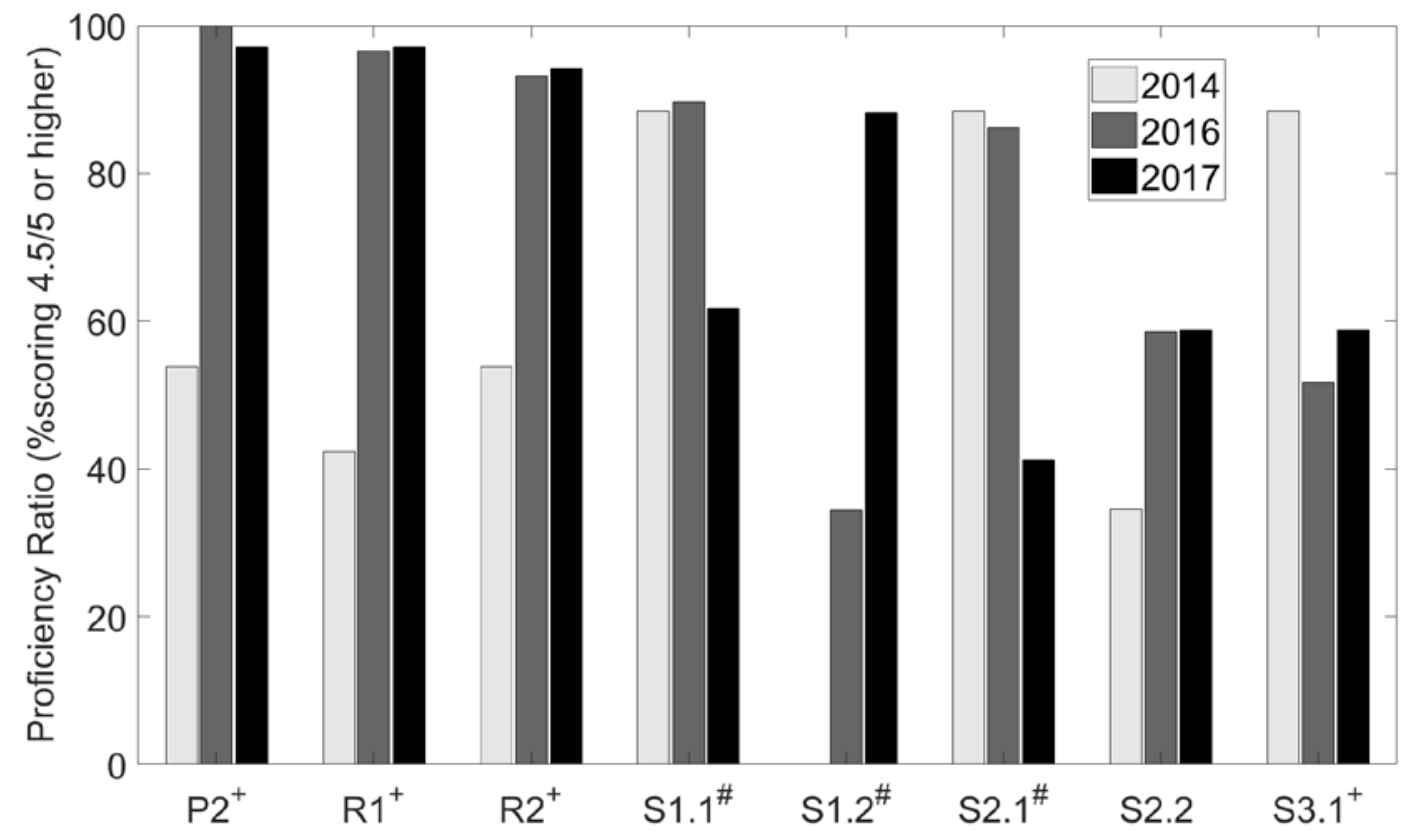

Figure 1: Comparing proficiency rate between 2014, 2016, and 2017. ${ }^{+}$Chi-Squared $p<0.02$ between 2014 and 2016, ${ }^{*}$ Chi-Squared $p<0.02$ between 2016 and 2017, indicating a significant difference between the two years. Chi-Squared $p=0.08$ for skill S2.2 (2014-2016). Skills labeled with 2016 skills. Data are not available for Skill S1.2 in 2014.

Priorities matter in any course structure. The effect is only amplified in a mastery-based learning scheme. In 2016, few students mastered the general use of energy and momentum to analyze dynamic systems. Many struggled to identify where to apply energy vs. momentum analysis and with the correct implementation of rotational terms. In 2017, students were encouraged to develop this particular skill for the reasons described above, by moving the skill up from a supplemental skill to a required skill.

Then, yes, when forced to continue to practice this skill and demonstrate mastery before moving on, students did just that. Students still struggled with the mastery of this skill, but the proficiency rate went from $34 \%$ to $88 \%$. Students now had to demonstrate proficiency on this skill to gain access to B-level grades. In 2016, failure to master this skill had less impact on grades. However, because of this change students had less time to master skills S1.1 and S2.1, and those proficiency rates dropped sharply.

\section{General Discussion and Conclusions}

At the root of this grading system is the balance of breadth and depth. Think of the methodology as moving from a grade based on how well a student can do everything covered in the course to how many of the skills covered in the course that student can do well. As such, the method demands that the course content can be distilled into a handful of critical skills. Moreover, mastery of those 4 (or so) skills is sufficient to earn the grade necessary to satisfy any prerequisites. 
The comparisons to the 2014 course must be interpreted carefully. The definition of student success was reframed with this competency-based system of grading. In the comparisons between the offerings, the new paradigm was used as the basis of comparison. In the end, the metric for evaluating student success was modified, and the students followed that lead.

This grading system favors developing a higher level of proficiency in fewer skills over a lower level of proficiency in more skills. The top students in both cases arrive at a similar endpoint with full proficiency across all the skills. The difference exists moderately in the average student and more strongly in the lowest performing students. Final grades in the course did not change from the traditional grading system (Table 4).

Table 4: Grade distribution across the two models.

\begin{tabular}{|c|c|c|}
\hline Grade Range & Traditional (2014 and 2015) & Competency (2016 and 2017) \\
\hline A and A- & $28 \%$ & $28 \%$ \\
\hline B+, B, and B- & $38 \%$ & $34 \%$ \\
\hline C+, C, and C- & $31 \%$ & $30 \%$ \\
\hline D+, D, and D- & $0 \%$ & $6 \%$ \\
\hline F & $3 \%$ & $2 \%$ \\
\hline
\end{tabular}

Demonstrating mastery on one problem does not indicate mastery in all similar situations. Still, this limitation persists across all grading paradigms. In both cases though, success in the assessment should correlate strongly with the ability to analyze a novel system or solve a new problem of similar type.

At first, students resisted this grading methodology. Many of the strongest students were concerned with their grade-to-date throughout the semester. However, those same students found they preferred the system by the end of the semester. In the second year, by better managing the system and explaining the process and the reasons for using the method, the students were more accepting of the structure. In 2017, IDEA evaluations (https://www.ideaedu.org/) were available for the mastery-based offering of the course. In those evaluations, the students indicated validation of the grading system: "[I] loved the grading system." Several specific IDEA results connected to the grading system support the idea that students took responsibility for their learning, pushed themselves beyond typical courses, and understood the grading mechanism (Table 5).

In the first year, 2016, every table (5-6 students) was allowed to choose their own activities during coaching sessions. In this environment, the instructor struggled to provide meaningful coaching to the students, only able to spend a total of 10-15 minutes with each group. By controlling which problems the groups worked on and limiting the group division to two sets, the instructor could triple the time spend with each larger group in a given session. As a result in the second year, students valued the coaching sessions far more than they had in the first offering. In fact, students requested that the quiz session be moved to the evening so that they do not have to miss a coaching session when taking a skill assessment. 
Table 5: Student response to the course in a traditional offering, 2015, and a competency-based offering, 2017 (IDEA). IDEA evaluations were not conducted in 2014 or 2016.

\begin{tabular}{|l|c|c|}
\hline IDEA prompt (scale of 1-5) & \multicolumn{2}{|c|}{ Student Rating } \\
\hline & 2015 & 2017 \\
\hline Found ways to help students answer their own questions & 4.2 & 4.3 \\
\hline Asked students to help each other understand ideas or concepts & 3.8 & 4.3 \\
\hline $\begin{array}{l}\text { Stimulated students to intellectual effort beyond that required by most } \\
\text { courses }\end{array}$ & 4.1 & 4.4 \\
\hline Demonstrated the importance and significance of the subject matter & 3.9 & 4.3 \\
\hline Made it clear how each topic fit into the course & 4.0 & 4.4 \\
\hline $\begin{array}{l}\text { Provided timely and frequent feedback on tests,...to help students } \\
\text { improve }\end{array}$ & 4.2 & 4.6 \\
\hline Gave tests,...that covered the most important points of the course & 4.3 & 4.7 \\
\hline
\end{tabular}

In the 2016 offering, no sessions were dedicated to the introduction of the skills, but rather a series of two or three 10-15 minute videos were offered in a flipped classroom model. Many students struggled to learn new concepts effectively from the videos. The students did much better in 2017 with the in-class sessions. The videos were still posted in the course management system so that students behind in the skills could go back to that material when they were actively working on mastering that skill.

In the second year, 2017, the instructor explicitly highlighted the advantages of learning by doing [15] and allowing students to take the time they need to master each topic before moving on to the next [9]. Different students need different volumes of practice to master various skills. Pushing students forward before they have mastered fundamentals only sets them up for continued failure.

One student who typically earned B's and C's in engineering courses, after working hard to pass the first set of skills commented "I am hanging this on the wall. It is the first time I ever got an A on a test in Engineering." While she again finished the course with a C, the attitude was completely different. She had a new confidence in the discipline. She could master this material; it just took her a little longer than some others. Students found that they were less stressed about exams, "If I don't pass it today, there's always next week." They could focus on an appropriate number of skills for them. "I'm ready for R2 today; I'll work on R3 for next week.” Students appeared to take more personal responsibility for their learning.

In the future, a more traditional final exam covering the breadth of the course could be given for a more direct comparison to the 2014 final exam. The 2014 students did not have as many opportunities to demonstrate the skills, so perhaps they did not need more practice, just more attempts. Qualitative observations suggest this is not the case, but no empirical evidence supports this claim.

In conclusion, this case study indicates that with the additional time and practice students who otherwise would have been content to "sort of understand" and move on could and did learn to fully apply the required skills. Moving to a competency-based grading scheme created an 
environment where students mastered a few critical skills, at the expense of giving up a broader coverage of topics for average students.

\section{References}

[1] M. Henri, M. . D. Johnson and B. Nepal, "A review of Competency-Based Learning: Tools, Assessments, and Recommendations," Journal of Engineering Education, vol. 106, no. 4, pp. 607-638, 2017.

[2] R. W. Tyler, Basic Principles of Curriculum and Instruction, Chicago: University of Chicago Press, 2013.

[3] B. S. Bloom, "The 2 sigma problem: The search for methods of group instruction as effective as one-to-one tutoring," Educational Researcher, vol. 13, no. 6, pp. 4-16, 1984.

[4] E. A. Roe and T. Bartelt, "Converting a Traditional Engineering Technology Program to a Competency-based, Self-paced, Open-entry/Open-exit Format," in ASEE Annual Conference \& Exposition, Seattle, 2015.

[5] T. Brumm, S. Mickelson, B. L. Steward and A. Kaleita, "Competency-based outcomes assessment for agricultural engineering programs," International Journal of Engineering Education, vol. 22, no. 6, p. 1163-1172, 2006.

[6] R. M. Felder, R. Brent and M. J. Prince, "Engineering Instructional Development: Programs, Best Practices, and Recommendations," Journal of Engineering Education, vol. 100, no. 1, p. 89-122, 2011.

[7] J. E. Froyd, P. C. Wankat and K. A. Smith, "Five Major Shifts in 100 Years of Engineering Education," Proceedings of the IEEE, vol. 100, pp. 1344-1360, 2012.

[8] W. G. Spady, "Competency based education: A bandwagon in search of a definition," Educational Researcher, vol. 6, no. 1, pp. 9-14, 1977.

[9] T. R. Guskey, "Lessons of Mastery Learning," Educational Leadership, vol. 68, no. 2, pp. 52-57, October 2010.

[10] B. S. Bloom, Human Characteristics and School Learning, New York: McGraw-Hill, 1976.

[11] T. R. Guskey and T. D. Pigott, "Research on group-based mastery learning programs: A meta-analysis," The Journal of Educational Research, vol. 81, no. 4, pp. 197-216, 1988.

[12] C.-L. C. Kulik, J. A. Kulik and R. L. Bangert-Drowns, "Effectiveness of Mastery Learning Programs: A Meta-Analysis," Review of Educational Research, vol. 60, no. 2, pp. 265-299, 1990.

[13] L. E. Craugh, "Adapted Mastery Grading for Statics," in ASEE, Columbus, Ohio, 2017.

[14] S. L. Post, "Standards-Based Grading in a Fluid Mechanics Course," in ASEE, Indianapolis, 2014.

[15] S. Freeman, S. L. Eddy, M. McDonough, M. K. Smith, N. Okoroafor, M. P. Wenderoth and H. Jordt, "Active learning increases student performance in science, engineering, and mathematics," Proceedings of the National Academy of Sciences, vol. 111, no. 23, pp. 8410-8415, June 2014. 